Revista Monografias Ambientais - REMOA v. 14, 2015, p. 92 -106

EDIÇÃO ESPECIAL: PÓS GRADUAÇÃO EM EDUCAÇÃO,

INTERDISCIPLINARIDADE E TRANSVERSALIDADE

- UNIPAMPA - SÃO GABRIEL - RS

Revista do Centro de Ciências Naturais e Exatas - UFSM, Santa Maria

\title{
A educação ambiental no serviço militar obrigatório: uma abordagem prática
}

\author{
The Environmental Education in Military Service Required: A Practical Approach \\ Ivonir Gonçalves Leher ${ }^{1}$, Jefferson Marçal da Rocha ${ }^{2}$ \\ ${ }^{1}$ Bacharel em Filosofia e Especialista em Educação: Interdisciplinaridade e Transversalidade, \\ Universidade Federal do Pampa, São Gabriel, RS, Brasil. \\ ${ }^{2}$ Doutor em Meio Ambiente e Desenvolvimento, Professor Associado da Universidade Federal do Pampa, São Gabriel, RS, Brasil.
}

\begin{abstract}
Resumo
O presente artigo tem como temática principal o ensino da Educação Ambiental no âmbito das Forças Armadas, em especial no Exército Brasileiro. A Unidade em que foi desenvolvido este trabalho localiza-se no município de São Gabriel/RS. Este tema é de extrema importância na formação dos jovens, especialmente os recrutas que muitas vezes buscam no serviço militar sua profissão ou a continuidade de sua preparação para o mercado de trabalho. O objetivo compreender como a temática ambiental é tratada no âmbito das Forças Armadas e a partir daí desenvolver atividades com os recrutas da $13^{a}$ Companhia de Comunicações Mecanizado. O artigo faz um estudo das origens do Serviço Militar Obrigatório e analisa o papel do Exército enquanto instituição formadora de cidadãos. Usou-se como metodologia um referencial teórico sobre os temas pertinentes e aplicou-se um questionário com a finalidade de conhecer o grau de escolaridade, as condições sócio-econômicas e o nível de conhecimentos dos jovens quanto aos temas referentes à questão ambiental contemporânea. Após a análise destes questionários, foram ministradas oficinas com a finalidade de auxiliar, os recrutas na compreensão da importância de se adotar novas posturas em relação à questão ambiental. Os resultados indicam que a prática constante de medidas de conscientização e incentivo quanto à consciência da preservação do meio ambiente, podem mudar hábitos de consumo, perspectivas éticas e estabelecer uma consciência planetária, promovendo assim uma mudança de atitudes frente aos problemas enfrentados pela sociedade atual.
\end{abstract}

Palavras-chave: Exército, Educação, Sociedade, Sustentabilidade.

\begin{abstract}
This article has as main theme the environmental education teaching in the Armed Forces, especially in the Brazilian Army. The unit that was developed in this work is located in the municipality of São Gabriel / RS. Issue of utmost importance in the formation of young people, especially those recruits who often come in the military profession or the continuation of his preparation for the labor market. Their goal was to develop activities with servicemen of the 13th Mechanized Company Communications, trying to understand how environmental issues are dealt with in the Armed Forces. The article is a study of the origins of compulsory military service and examines the role of the Army as a training institution for citizens. It was used as a theoretical reference methodology on relevant issues and applied a questionnaire in order to know the level of education, socio-economic conditions and the level of knowledge of young people about the issues related to contemporary environmental issues. After analyzing these questionnaires, classes were given in order to help develop a new attitude toward the subject. The results indicate that the constant practice of awareness and incentives as the awareness of environmental protection, can change consumer habits, ethical perspectives and establish a planetary awareness, thus promoting a change of attitude towards the current society.
\end{abstract}




\section{INTRODUÇÃO}

Este trabalho tem como objetivo analisar o ensino da Educação Ambiental no Exército Brasileiro. Busca apresentar a importância deste assunto na formação dos jovens recrutas que muitas vezes despertam no serviço militar obrigatório sua futura profissão ou a continuidade de sua preparação para o mercado de trabalho.

Alguns autores, como Leonardo Boff (2012) ao nos falar sobre a Carta da Terra, um dos mais importantes documentos sobre a questão da sustentabilidade, que ele próprio ajudou a construir, nos diz que "Estamos num momento crítico da história da Terra, num momento em que a humanidade deve escolher o seu futuro (...)"(BOFF, 2012, p.13). Cuidar da terra, cuidar do local onde vivemos e que deixaremos para nossos filhos e netos é um dever, uma obrigação de todos nós.

A nossa volta, em cada palmo de terra que percorremos, em cada gota de água que bebemos, no ar que respiramos, na luz do sol que nos concede a vida e faz crescer as plantas, a questão ambiental faz parte do nosso dia a dia, da nossa própria existência. A "convivência sustentável" (BOFF, 2012), nos faz refletir sobre os rumos que o nosso planeta vem seguindo nas últimas décadas no tocante a conservação do meio ambiente.

Segundo Jacobi (2003), a reflexão sobre as práticas ambientais é um compromisso de todos, da comunidade universitária que tem o papel de instigar a reflexão e dar parâmetros científicos para as ações políticas, dos educadores, que frente aos seus estudantes, deverão trazer estas questões para o diálogo, envolvendo, desta forma, os diversos atores do universo educativo e também de toda a comunidade, que deverá fazer parte das transformações sociais necessárias para uma efetiva sustentabilidade. Estas estratégias devem ser orientadas por propostas interdisciplinares, unindo as mais diversas áreas do conhecimento em prol de um bem comum, a preservação da vida.

Assim, a questão ambiental contemporânea exige uma nova reflexão sobre o papel de cada área do conhecimento. Aspectos sociais e culturais devem ser levados em consideração quando estabelecemos este diálogo, procurando delinear todos os setores, o desafio é produzir conhecimento que esteja ligado à preservação ambiental. Um destes desafios será mudar a forma de pensar e de agir em sociedade, buscando soluções para equilibrar desenvolvimento e sustentabilidade.

Pensar sustentabilidade é um dever de todos, mas, para isso, também precisamos compreender, de fato, o que significa ser sustentável, pois, no último quarto do século $X X$, o termo sustentabilidade instigou uma reflexão sobre os modos de produção de riquezas (ROCHA, 2011).

O sociólogo alemão Ullrich Beck (1992), por exemplo, nos apresenta a concepção de "Sociedade de risco", levantando questões como acidentes nucleares, contaminações por agentes químicos e biológicos e mutações genéticas, fatores que tornaram o planeta um local "perigoso" para viver, e nos faz refletir se esta é uma tendência natural do desenvolvimento das ciências, da tecnologia e da economia globalizada difundida pela nova fase do capitalismo.

O mesmo pesquisador também nos traz o conceito de "modernidade reflexiva", caracterizada por uma sociedade que vive em um ambiente onde os riscos são de alta gravidade, exigindo diálogo e entendimento, e é neste espaço que a informação direcionada para melhorar as condições de vida no planeta deve se desenvolver (BECK, 1992). 
Neste processo, todos precisam ser responsáveis e conscientes, mudando padrões de comportamento individuais e coletivos, estabelecendo novas relações de consumo, buscando, não só a qualidade de vida, mas na manutenção dos recursos naturais fundamentais para esta qualidade. Jacobi (2003) recorre a conceitos de Vigotsky (2003), como a internalização de significação, trazendo para a escola parte desta responsabilidade de reconstrução interna do indivíduo, ao receber informações externas como reciclagem do lixo, desmatamento, poluição atmosférica, entre outros temas.

Partindo destes autores, podemos considerar que a questão ambiental deve nascer na convivência familiar, na orientação dos filhos para que cuidem dos recursos naturais, da utilização consciente dos bens de consumo, para que não se tornem adultos inconsequentes e consumistas, passando pelo papel fundamental da escola na troca de conhecimentos entre mestre e aluno e por fim, na preparação para o trabalho.

Neste contexto, as Forças Armadas, por sua credibilidade e por ser uma grande escola formadora de cidadãos, precisa integrar-se de maneira mais ativa a esta nova expectativa social, de mudança para um mundo mais sustentável, contribuindo com sua didática e seus programas de instrução para que os jovens que prestam o serviço militar obrigatório tenham um contato mais direto com a temática de Educação Ambiental, assunto este que faz parte dos Temas Transversais da Educação, previstos nos Parâmetros Curriculares Nacionais (PCNs).

O Exército, neste sentido, já faz parte do processo, conforme observamos em diversos documentos, dentre eles a Portaria 1138/10 que aprova a Política de Gestão Ambiental do Exército Brasileiro, determinando, dentre outras atividades, a "manutenção do equilíbrio ecológico e da sustentabilidade, considerando o meio ambiente como um patrimônio público a ser assegurado e protegido; a racionalização do uso do solo, subsolo, água, ar e recursos vegetais" (PGAEB, 2010, p. 2), bem como a proteção da fauna e controle de atividades potencial ou efetivamente poluidoras, determinando ainda que todo militar, individualmente ou enquadrado em organismo coletivo, é responsável por cumprir a legislação ambiental vigente no País.

Também o RISG, Regulamento Interno dos Serviços Gerais, em seu Art. 286 diz o seguinte:

Em continuidade ao tradicional zelo e à salutar convivência do militar com o meio ambiente, o controle ambiental, no âmbito da unidade, visa a orientar, educativa e preventivamente, todos os integrantes da OM sobre os cuidados e o respeito à Natureza, durante a execução de atividades diárias e operacionais da unidade (EB, 2003, p. 78).

Destarte, com a finalidade de realizar um estudo sobre o papel das Forças Armadas na formação intelectual dos jovens recrutas, incorporados todos os anos nas diversas unidades do Exército e considerando nossa atuação profissional ${ }^{1}$, desenvolvemos um trabalho de intervenção educativa junto aos recrutas da 13 $3^{\text {a }}$ Companhia de Comunicações Mecanizada, Unidade do Exército localizada em São Gabriel, RS.

Este trabalho está dividido em seis tópicos além desta introdução: o primeiro trata da questão ambiental na época contemporânea, a evolução do tema, desde a Conferência de Estocolmo até os dias atuais; o segundo trata do Serviço Militar Obrigatório, das origens do Serviço Militar no Brasil e a forma como é conduzido; o terceiro, da Educação Ambiental nas Forças Armadas. A metodologia que foi adotada para realizar esta pesquisa está no tópico quarto; já a análise dos resultados obtidos com a

1 Bacharel em filosofia e sargento do Exército Brasileiro. 
aplicação da pesquisa e com a realização da intervenção é o tópico quinto; e por último, são explicitadas as considerações finais a respeito do trabalho realizado.

\section{A QUESTÃO AMBIENTAL NA ÉPOCA CONTEMPORÂNEA}

A questão ambiental no campo filosófico não é nova. Segundo Marilena Chauí (2000), ao comparar os filósofos modernos Francis Bacon e Renê Descartes com os filósofos da antiguidade como Sócrates ou Aristóteles, por exemplo, estes já prenunciavam a dominação do homem sobre a natureza, da ciência sobre a realidade que nos cerca, como observamos neste trecho de Convite à Filosofia:

\footnotetext{
Duas afirmações mostram a diferença dos modernos em relação aos antigos: a afirmação do filósofo inglês Francis Bacon, para quem "saber é poder", e a afirmação de Descartes, para quem "a ciência deve tornar-nos senhores da Natureza". A ciência moderna nasce vinculada à ideia de intervir na Natureza, de conhecê-la para apropriar-se dela, para controlá-la e dominá-la. A ciência não é apenas contemplação da verdade, mas é sobretudo o exercício do poderio humano sobre a Natureza. Numa sociedade em que o capitalismo está surgindo e, para acumular o capital, deve ampliar a capacidade do trabalho humano para modificar e explorar a Natureza, a nova ciência será inseparável da técnica (CHAUÍ, 2000, p. 324).
}

Por esta citação, percebe-se que a evolução da ciência, da industrialização, do domínio do capital sobre as relações humanas, com a finalidade de ampliar a capacidade de trabalho, é capaz de subjugar os recursos naturais com o objetivo de extrair da natureza cada vez mais, sem se preocupar com sua preservação.

No campo político, a questão ambiental passou a ser tratada mais tarde pelo Clube de Roma, que publicou em 1968, o relatório Limites do Crescimento (ROCHA, 2012). Em 1972 foi realizada a Conferência de Estocolmo, onde ocorreu a Primeira Conferência Mundial sobre o Homem e o Meio Ambiente, e a partir desse marco, a humanidade pode perceber a grave degradação ambiental a nível internacional. Na Conferência de Estocolmo, propostas como o controle do crescimento demográfico da população mundial e do cuidado com o avanço da industrialização foram levantadas, expondo para o mundo problemas imperceptíveis e pouco divulgados para a época, como aquecimento global, diminuição da camada de ozônio, descongelamento das calotas polares, entre outros (ROCHA, 2011; JACOBI, 2003). Estes dois acontecimentos foram decisivos para alertar as Nações Unidas sobre uma realidade preocupante e um futuro sombrio, caso medidas urgentes não fossem tomadas. A partir desta conferência, a ONU criou o Programa das Nações Unidas para o Meio Ambiente (PNUMA).

Em 1984, sob o lema "Uma agenda global para a mudança”, realizou-se a "Comissão Mundial sobre o Meio Ambiente e Desenvolvimento", composta por dezenas de especialistas que encerram seus trabalhos em 1987 com o Relatório Brundtland intitulado “Nosso futuro comum” (BOFF, 2012).

A Assembleia das Nações Unidas com a proposta de dar continuidade a esta discussão, convocou a Conferência das Nações Unidas sobre Meio Ambiente e Desenvolvimento, realizada no Rio de Janeiro em julho de 1992, evento este que ficou conhecido como a Cúpula da Terra, ou Rio 92. Nesta conferência, diversos documentos foram produzidos, sendo os principais a Agenda 21: Programa de Ação Global e a Carta do Rio de Janeiro, onde firmou-se o compromisso da "parceria global para a conservação, proteção e restauração da saúde e da integridade dos ecossistemas terrestres" (BOFF, 2012, p.35), atribuindo responsabilidades e exigindo o comprometimento de todos os países participantes. 
Também na Rio 92, o Tratado de Educação Ambiental para Sociedades Sustentáveis e Responsabilidade Global apresentou um "plano de ação para educadores ambientais, estabelecendo uma relação entre as políticas públicas de educação ambiental e a sustentabilidade" (JACOBI, 2003, p. 194). Esta proposta estabeleceu a participação comum, com a finalidade de promover a melhoria da qualidade de vida, buscando a recuperação e a conservação do meio ambiente. Infelizmente, houve pouco empenho dos países envolvidos, como observou-se na Riọ + 5, realizada em 1997, também no Rio de Janeiro. Segundo Leonardo Boff (2012, p.35) “a lógica capitalista que procura maximizar os lucros em detrimento das desigualdades sociais" falou mais alto e pouco cumpriu-se do acordo firmado.

Dez anos mais tarde, em 2002, na chamada Rio + 10 em Joanesburgo, África do Sul, a ONU convocou uma nova Cúpula da Terra, com a finalidade de tratar sobre Sustentabilidade e Desenvolvimento, reunindo representantes de 150 nações. Ao contrário da Eco 92, desta vez, ao invés da cooperação, prevaleceu a disputa por interesses econômicos (BOFF, 2012) onde os países mais desenvolvidos boicotaram a discussão sobre fontes de energia alternativas, imperando mais uma vez o poder do capital. Já na Rio + 20, ocorrida em 2012, mais uma vez no Rio de Janeiro, apesar dos inúmeros chefes de Estados que participaram, os acordos firmados foram pífios. Entretanto, os avanços ocorreram entre os membros da Sociedade Civil Organizada, especialmente as ONGs, que provocaram movimentos e protestos que acabaram repercutindo mais efetivamente entre a comunidade mundial.

No campo da ética, o filósofo alemão Hans Jonas (apud ALENCASTRO, 2009), enfatiza que na sociedade contemporânea, onde o capitalismo dita as regras de ação e conduta, o ambiente natural é visto "apenas como fonte de matéria-prima para a produção de mercadorias, e a natureza como algo aberto e disponível para todo tipo de manipulação e exploração técnico-científica com fins econômicos" (ALENCASTRO, 2009, p. 14).

Esta preocupação ética nos impõe a reflexão sobre a responsabilidade de cada cidadão e em especial dos órgãos governamentais em não permitir que a natureza seja vista apenas como uma fonte inesgotável de recursos, pois o futuro da vida no planeta depende do comprometimento da sociedade. A geração tecnológica, consumista, descarta produtos altamente poluentes como equipamentos eletrônicos, celulares, computadores, na mesma medida em que adquire as novas tecnologias despejadas no mercado todos os dias.

Mas fica a pergunta: vale a pena tanta tecnologia? Até que ponto nosso planeta pode resistir a tanta agressão? Esta preocupação nos remete à questão da sustentabilidade, ou seja, como obter da natureza os meios para a manutenção da vida sem degradá-la.

Para manter o equilíbrio dos ecossistemas e entender um pouco dessa dinâmica, recorremos a duas noções de sustentabilidade: sustentabilidade ecológica e sustentabilidade social exposta no livro Sustentabilidade em Questão (ROCHA, 2011). Segundo este autor, a noção de sustentabilidade ecológica é o estado de equilíbrio dos ecossistemas, que através da evolução criou mecanismos de reação às agressões que não necessariamente são interferências humanas, mas do próprio meio, chamados de resiliência, que é a "habilidade dinâmica de um sistema retornar a um estado de equilíbrio após uma perturbação" (ROCHA, 2011, p. 16). Evitar a perda de diversidade é o grande desafio, pois "quanto maior a resiliência, menor a probabilidade de extinção das espécies" (ROCHA, 2011, p. 16).

Quando a questão ambiental não atinge apenas a os ecossistemas mas também a sociedade humana, independente do local e da forma como se vive, entramos na segunda noção de sustentabilidade proposta por Rocha (2011), a sustentabilidade social, que leva em consideração as 
questões econômicas, políticas e sociais. O conforto e a riqueza de alguns privilegiados, amplia a desigualdade de acesso aos recursos produzidos, reforçando a pobreza da maioria e acentuando os problemas ambientais, realidade visível nas periferias das cidades.

A preocupação com esta realidade socioambiental, que nos cerca, está também presente na atual Encíclica Papal (2015), já chamada por muitos de "Encíclica verde", documento emitido pelo Papa Francisco que recomenda a humanidade e a todos os cristãos o cuidado com o planeta, para a preservação e manutenção da vida na Terra. Neste documento, o Papa Francisco (2015) alerta que "numerosos estudos científicos indicam que a maior parte do aquecimento global das últimas décadas é devida à alta concentração de gases com efeito de estufa emitidos sobretudo por causa da atividade humana"(PAPA FRANCISCO, 2015, p. 21).

O Sumo Pontífice da Religião Católica também chama a atenção para o perigo da extinção de muitas espécies de vida no planeta, dizendo que "Se a tendência atual continuar, este século poderá testemunhar mudanças climáticas inéditas e uma destruição sem precedentes dos ecossistemas, com graves consequências para todos nós" (PAPA FRANCISCO, 2015, p. 22). Adicionalmente, convoca a humanidade para mudanças nos hábitos de consumo, no estilo de vida e de produção e ainda, acusa os países ricos de fraqueza política e submissão perante os interesses econômicos, o que acaba prejudicando apenas os menos favorecidos.

\section{SERVIÇO MILITAR OBRIGATÓRIO: DA ORIGEM AOS DIAS ATUAIS}

O Serviço Militar Obrigatório no Brasil começou no período das Capitanias Hereditárias, com o intuito de oferecer resistência contra estrangeiros e índios rebeldes. Em setembro de 1542, na Câmara de São Vicente, foi promulgado um "Termo", organizando uma milícia formada por colonos e índios. Em 1548, os donos de engenho e os colonos recebem a determinação de possuírem armas para sua defesa, evidenciando o estabelecimento de uma organização militar, com o objetivo de defender a terra (ENCARNAÇÃO FILHO, 2003).

Na chamada Provisão Régia de 1574, foi instituído no Brasil a obrigatoriedade do serviço militar sendo esta a primeira legislação disciplinadora. No período imperial e após a independência do Brasil, foi reafirmada a obrigatoriedade do Serviço Militar, conforme o Art. 145 da Constituição de 1824 (BRASIL, 1824), ao determinar que todos os brasileiros são obrigados a pegar em armas para sustentar a independência do Império e defendê-lo de seus inimigos. Em 1908 esta obrigatoriedade foi regulamentado pelo Marechal Hermes da Fonseca, então Ministro da Guerra, porém sua efetivação só ocorreu após uma campanha nacional, iniciada pelos "jovens turcos", assim chamados os capitães e tenentes do Exército que haviam estagiado na Alemanha, iniciando novas e importantes mudanças no Exército Brasileiro.

Vários intelectuais, dentre eles Olavo Bilac, atual Patrono do Serviço Militar, Rui Barbosa e Coelho Netto, criaram a Liga de Defasa Nacional, com a finalidade de divulgar o Serviço Militar entre os jovens, através de palestras e cartilhas. Vivia-se o fantasma da Primeira Guerra Mundial e precisava-se eliminar as "ideias anarquistas", fundindo na sociedade a ideia de Pátria e Nação brasileira (KUHLMANN, 2001). Começava aí a importante fusão Exército-Sociedade, que se perpetua até os nossos dias.

Em 1916, o Serviço Militar Obrigatório foi implantado, com poucas mudanças até os dias atuais e, em agosto de 1964, foi promulgada a Lei do Serviço Militar, válida até hoje, que obriga a todos os 
jovens do sexo masculino, que completam 18 anos de idade, a prestação do Serviço Militar por aproximadamente 11 meses.

Anualmente, cerca de 70 mil jovens de diferentes classes sociais, graus de escolaridade, culturas e características étnicas ingressam nas fileiras do Exército, Marinha e Aeronáutica. Há uma disparidade muito grande no nível intelectual dos jovens recrutas, pois enquanto muitos destes jovens possuem apenas o ensino fundamental incompleto, outros já estão cursando a Universidade. Considerada uma escola de formação de cidadãos e com uma inegável credibilidade junto à opinião pública do nosso país, o papel das Forças Armadas na educação destes jovens tem sido objeto de estudo em diferentes áreas do conhecimento.

Quanto à questão da obrigatoriedade do Serviço Militar, Orlando Pessanha da Encarnação Filho (2003) observa em seu estudo que:

\begin{abstract}
Em verdade, os jovens que por aqui passam, consideram o Exército uma "grande escola de vida" onde, além de aprenderem a fazer uso de material bélico e técnicas de combate, incorporam valores com solidariedade, confiança, entusiasmo, determinação e perseverança, ferramentas que lhe permitirão levar a bom termo sua missão de soldado e sua vida de cidadão. Dessa forma, o Exército integra à força de trabalho do país um preparado contingente de jovens aptos a exercerem a plena cidadania. As forças armadas, antes estruturas fechadas, estão abrindo seus portões para um mundo moderno, frente à necessidade de preparar os jovens soldados para exercer uma profissão em um mundo cada dia mais competitivo e moderno. O preparo para a Guerra deixou de ser o foco único da instituição. (ENCARNAÇÃO FILHO, 2003, p. 79).
\end{abstract}

Segundo dados do Ministério da Defesa, no ano de 2014, 1,7 milhão de jovens se alistaram para ingresso nas Forças Armadas e cerca de 100 mil foram incorporados.

Nas Unidades de tropa, logo após a incorporação dos novos soldados, tem início o ano de instrução, dividido em dois períodos distintos: a Instrução Individual Básica, com duração de 8 semanas e a Instrução Individual de Qualificação, com duração de 12 semanas. Nesta, os novos soldados são preparados para desempenhar atividades específicas, nas funções que ocuparão até o final do período de serviço militar, qualificados nas áreas de comunicações, aprovisionamento, mecânica, etc. É no período de Instrução Individual Básica que ocorrem as instruções sobre temas como Ética e Meio Ambiente.

Tomando como pano de fundo os Temas Transversais da Educação, procuramos, através deste trabalho, observar o ensino de Educação Ambiental em uma Unidade do Exército Brasileiro, durante o período de Instrução Individual Básica no ano de 2015. A Unidade escolhida para aplicarmos esta pesquisa foi a $13^{\text {a }}$ Companhia de Comunicações Mecanizada, situada na cidade de São Gabriel-RS, que teve neste ano 75 recrutas incorporados ao seu efetivo.

\title{
A EDUCAÇÃO AMBIENTAL NAS FORÇAS ARMADAS
}

Segundo o professor Ronaldo Costa, em sua dissertação de mestrado desenvolvida na FURG no ano de 2008, a consciência ambiental no Exército Brasileiro começou a se descortinar no final da década de 1990, adequando as atividades desenvolvidas pela força com os princípios de preservação ambiental vigentes na legislação brasileira, através da Política de Gestão Ambiental do Exército Brasileiro, "a qual 
se vê desdobrada e operacionalizada nos regulamentos, diretrizes, normas e demais documentos próprios da Força Terrestre" (COSTA, 2008, p. 172).

A Educação Ambiental faz parte do currículo obrigatório a ser ministrado no período de Instrução Individual Básica aos novos recrutas e também nas Escolas de Formação do pessoal de carreira do Exército. Esta preocupação não é de hoje, pois em 1973, foi criada a Secretaria Especial de Meio Ambiente, que estabeleceu como uma de suas atribuições "o esclarecimento e a educação do povo brasileiro para o uso adequado dos recursos naturais, tendo em vista a conservação do meio ambiente" (COSTA, 2008, p. 173).

A Política Nacional de Educação Ambiental (PNEA) através da Lei no 9795/99 (BRASIL, 1999), em seu Art. $7^{\circ}$, reforça que os órgãos públicos da União devem adotá-la em seu currículo, tanto na educação formal quanto na educação não-formal (COSTA, 2008). As Escolas de Formação como Academia Militar das Agulhas Negras onde são formados os oficiais e a Escola de Sargentos das Armas, responsável pela formação dos sargentos, bem como as demais escolas militares estão amparadas neste documento, sendo a educação não-formal caracterizada pela instrução ministrada nas Organizações Militares de tropa. Adicionalmente, Costa ressalta que:

A Educação Ambiental deve fazer parte do currículo dos cursos de formação dos militares de carreira, sejam sargentos ou oficiais, pois, ao concluírem ao término dessa formação, todos estarão habilitados a ser instrutores, atuando na formação de soldados ou de outros sargentos e oficiais. Já no aspecto não-formal, segundo a própria PNEA, a Educação Ambiental não-formal consiste em "ações e práticas educativas voltadas à sensibilização da coletividade sobre as questões ambientais e à sua organização e participação na defesa da qualidade do meio ambiente" (Art 13), devendo ser levada a efeito através da parceria com escolas, organizações não governamentais e comunidade local (COSTA, 2008, p. 174).

Somado a estas considerações, diversas portarias e regulamentos orientam e regulam a inserção e o trato com a Educação Ambiental nas atividades diárias das Organizações Militares, tanto nas atividades de ensino, quanto nas de instrução de cunho tipicamente militar. Mas, segundo Costa (2008), muitas vezes este assunto é relegado a segundo plano, como se não fizesse parte da formação de todos os cidadãos. Cabe lembrar que não bastam simples medidas, adotadas, na maioria das vezes, como campanhas pontuais de coleta de lixo ou limpeza de rios, mas a adoção efetiva e transformadora da realidade, que conscientize os jovens recrutas que vivem este momento de transformação.

Em São Gabriel e, especificamente, na 13 ${ }^{\text {a }}$ Companhia de Comunicações Mecanizada, o trato e o cuidado com a questão ambiental já perdura há alguns anos, com a adoção de medidas que já fazem parte do dia a dia da instituição. Tais medidas consistem de como coleta seletiva de lixo, a conscientização do público interno sobre a redução do consumo de energia, desperdício de água, etc., como podemos observar no relato do pesquisador militar Licielo Vieira (2014):

Na Organização Militar é estimulada e implantada a coleta seletiva de lixo, sendo para isso, realizado um trabalho de conscientização dos integrantes desta, com comunicação pessoal, palestras ministradas, distribuição de folders, vídeos explicativos no intuito de constatar a importância da reciclagem e iniciar o processo de reciclagem de lixo com a devida separação de plásticos, papéis, vidros e metais. Para isso, o local de disposição dos recipientes de coleta seletiva foi exposto em locais de fácil acesso aos militares, assim como ao serviço de recolhimento de lixo da cidade que é realizado por caminhões e agentes ambientais cadastrados que buscam este material entregando em cooperativas de reciclagem (VIEIRA, 2014, p. 49). 
Esta convivência diária, com atitudes que incentivam a preservação é estimulante para a prática da discussão do assunto Educação Ambiental. Este trabalho procura, a partir dos resultados coletados, incentivar as práticas ambientalmente corretas entre os recrutas da $13^{\text {a }}$ Companhia de Comunicações Mecanizada, intensificando as instruções sobre o tema, mostrando o que já vem sendo feito e, principalmente, proporcionando uma mudança de hábitos de consumo, para que estes jovens sejam os disseminadores da ideia de preservação do meio ambiente quando retornarem para suas casas e cidades de origem.

\section{METODOLOGIA DA PESQUISA}

Esta pesquisa utilizou como metodologia a pesquisa bibliográfica num primeiro momento, passo inicial na construção da fundamentação teórica acerca do tema e, na segunda fase, foi aplicado um questionário, composto de perguntas objetivas sobre as condições sócio econômicas e intelectuais do público estudado. Do tipo exploratória, teve como finalidade, traçar o perfil dos jovens incorporados na 13르 Cia Com Mec no ano de 2015, bem como identificar suas aspirações quanto a prestação do Serviço Militar Obrigatório. Neste questionário, observamos o grau de estudo do militar e de seus pais, a renda da família quantificada em salários mínimos, o nível de conhecimento dos recrutas referente ao assunto meio ambiente em questões como coleta seletiva de lixo, reciclagem, reaproveitamento de resíduos orgânicos, reflorestamento e preservação das águas.

A população de estudo foi composta de 46 jovens adultos do sexo masculino com idades entre 18 e 19 anos, oriundos das cidades de São Gabriel, Vila Nova do Sul, Santa Margarida do Sul, Muçum e Bom Retiro do Sul, todas do Rio Grande do Sul.

Após os dados coletados, foram realizadas palestras sobre a temática Educação Ambiental, onde foi abordado os seguintes temas: sustentabilidade planetária, legislação ambiental e responsabilidade da sociedade civil. Nestas palestras e oficinas, buscamos a cooperação de militares formados na área de Gestão Ambiental, trazendo para os jovens recrutas uma visão acadêmica sobre o assunto, além do previsto no programa de instrução. Também abordamos a legislação sobre os crimes ambientais e o papel constitucional do Exército no apoio a preservação do meio ambiente, sua atuação junto a outras instituições como Ibama e Polícia Federal.

Utilizou-se também dos exemplos que a Unidade vem demonstrando com relação a coleta seletiva, as parcerias realizadas com associações de catadores, dentre outras ações.

\section{ANÁLISE DOS RESULTADOS}

No quesito escolaridade, constatamos que a maior parte dos entrevistados, 32,61\% possui Ensino Médio Incompleto; 15,22\% o Ensino Médio Completo, e o mesmo percentual de 15,22\% possui o Fundamental Completo. Os que possuem o Ensino Fundamental Incompleto representam 30,43\%, 
enquanto apenas 6,52\% cursavam o Ensino Superior antes de servirem ao Exército, como observamos no gráfico 1 .

GRÁFICO 1: Grau de escolaridade dos recrutas

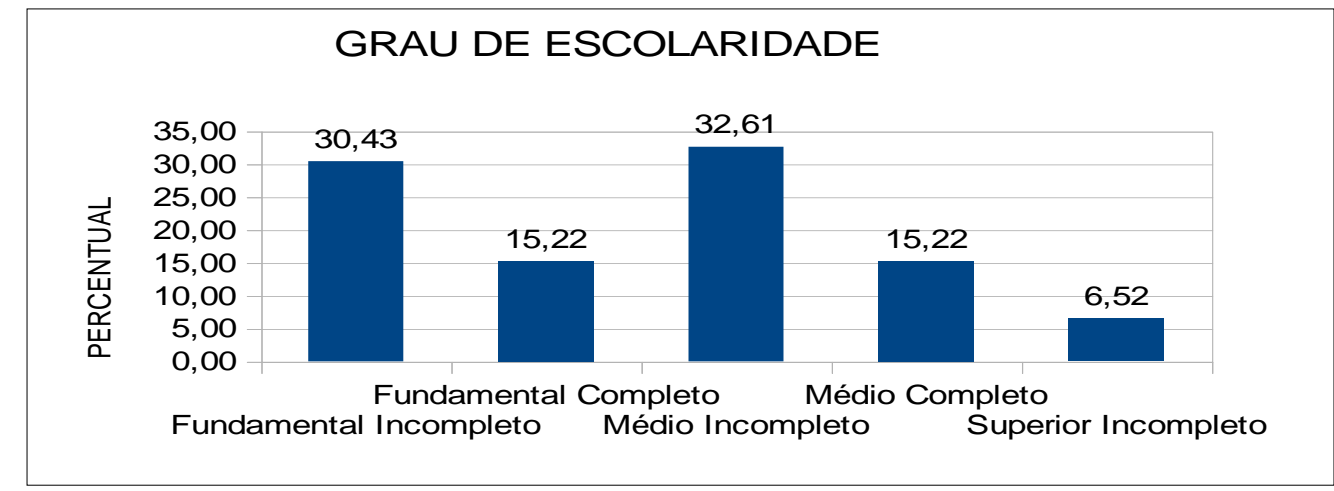

FONTE: Dados da pesquisa, 2015

Ainda neste universo, 63,04\% dos recrutas entrevistados, apenas trabalhavam antes de servirem; 21,74\% apenas estudavam e 15,22\% estudavam e trabalhavam (Gráfico 2).

GRÁFICO 2: Ocupação anterior ao serviço militar

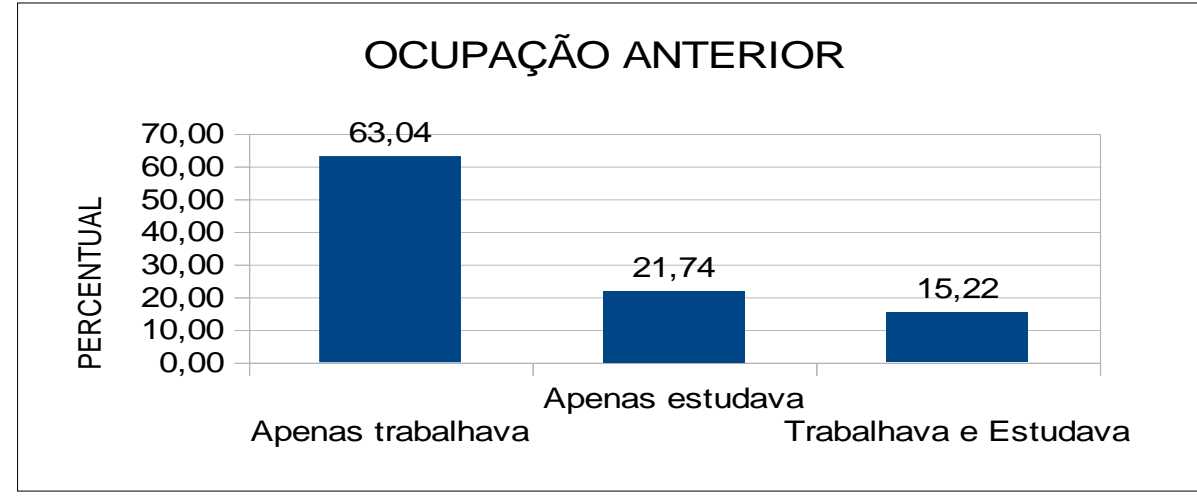

FONTE: Dados da pesquisa, 2015

Os voluntários para servir representaram um percentual de 63,04\%, enquanto 36,96\% não queriam servir ao Exército. (Gráfico 3)

GRÁFICO 3: Voluntários para servir ao Exército

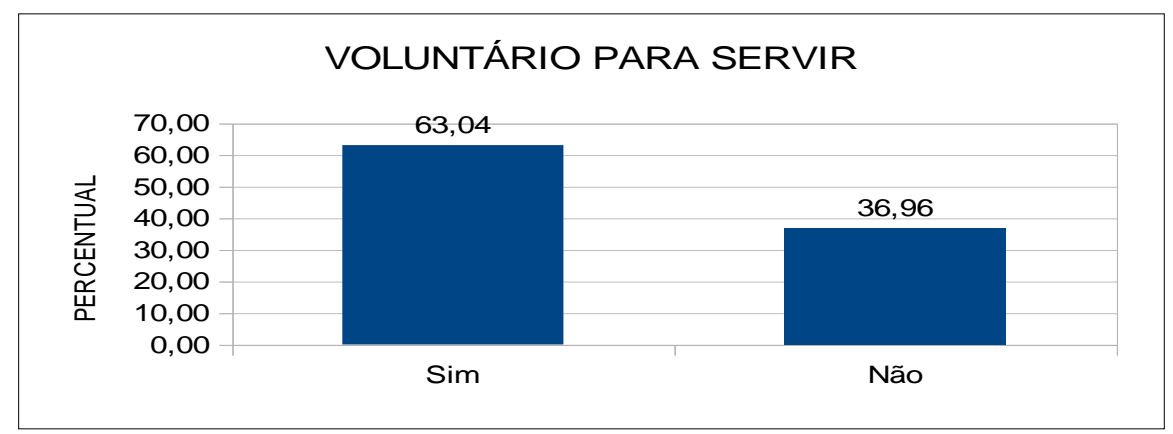

FONTE: Dados da pesquisa, 2015 
Quanto à possibilidade de continuar no Exército, 52,17\% gostaria de permanecer, enquanto $47,83 \%$ não demonstrou intenção de permanência, conforme podemos observar no gráfico 4 . Ao serem perguntados sobre a expectativa de continuar no Exército, aqueles que gostariam de ficar responderam na maioria das vezes que o que mais contribuía para esta escolha era a possibilidade de "ficar empregado" e receber um salário para ajudar no sustento da família.

GRÁFICO 4: Possibilidade de permanência no Exército

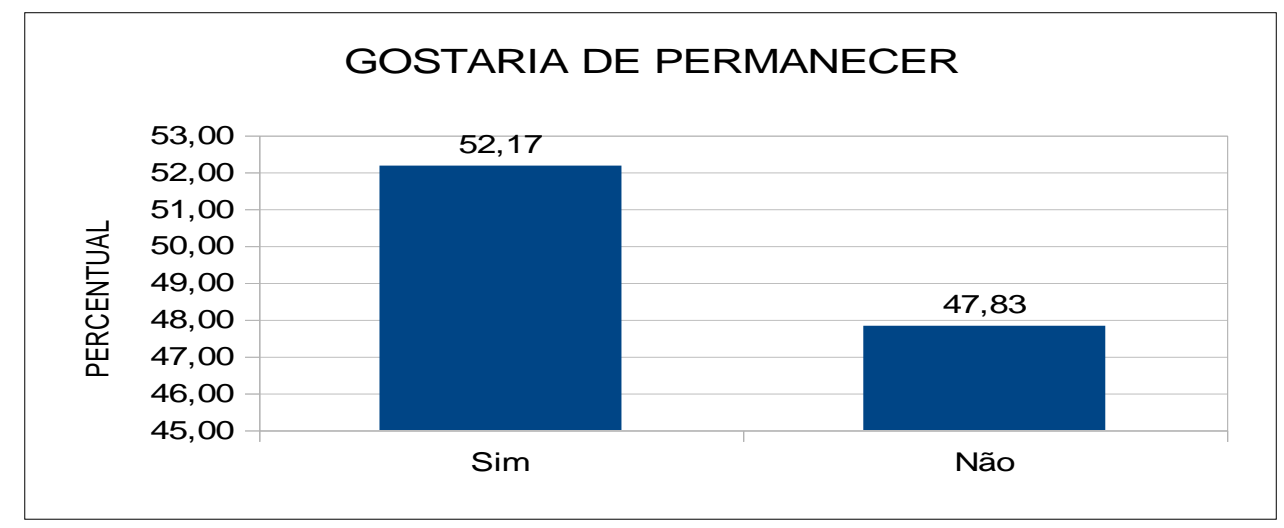

FONTE: Dados da pesquisa, 2015

Os que não gostariam de permanecer, alegam que a distância de casa é um grande empecilho e também que trabalhavam anteriormente, recebendo um salário melhor. Em ambos os casos, o que mais atrai os jovens é a questão salarial, mesmo que o tempo de permanência para o soldado seja relativamente curto.

As condições sócio econômicas das famílias também chama a atenção, pois mais da metade dos jovens pesquisados, 54,35\%, vive com uma renda familiar de 1 a 3 salários mínimos e na maioria dos casos, todos contribuem para o sustento familiar, onde desempenhavam atividades autônomas e informais como serventes de pedreiro, garçom, agricultura familiar, leiteiros, peões de estância, etc. (Gráfico 5)

GRÁFICO 5: Renda familiar 


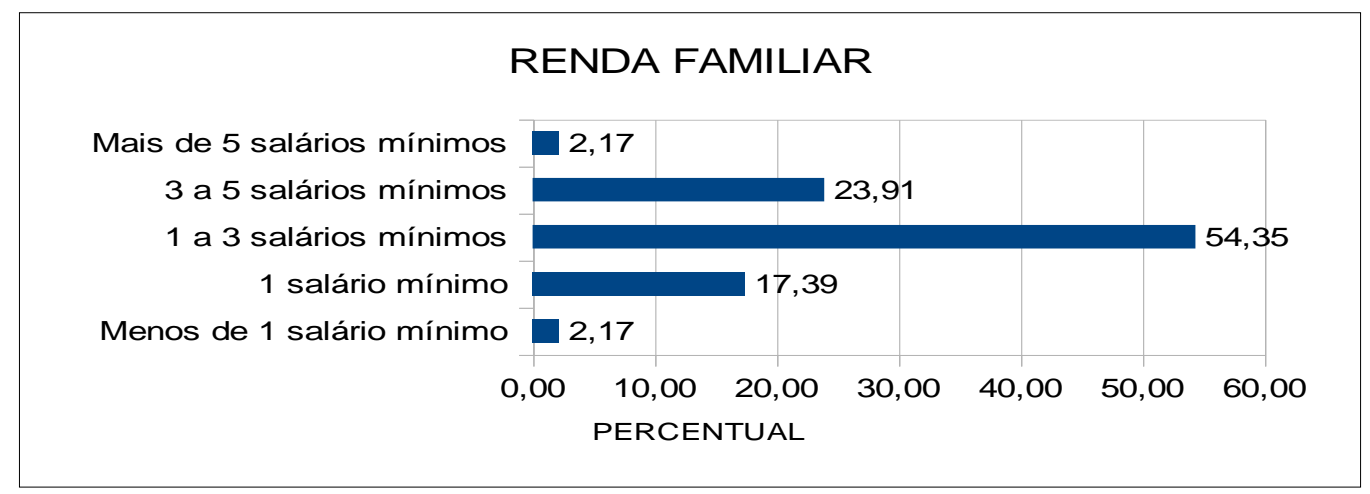

FONTE: Dados da pesquisa, 2015

Os naturais do município de São Gabriel-RS, trabalhavam na maioria dos casos sem carteira assinada, de maneira informal ou nos estabelecimentos comerciais da cidade. Os naturais de outros municípios onde existem indústrias calçadistas ou ligadas a outros setores industriais trabalhavam de maneira formal.

Na maioria dos casos, os pais também não concluíram os estudos, sendo que $50 \%$ possuem apenas o Ensino Fundamental Incompleto. Os que possuem o Fundamental Completo somam 13,04\%, Médio Incompleto 17,39\%, Médio Completo 10,87\% e Superior Incompleto 8,7\%. Nem um possui o Superior Completo. (Gráfico 6)

GRÁFICO 6: Escolaridade dos pais

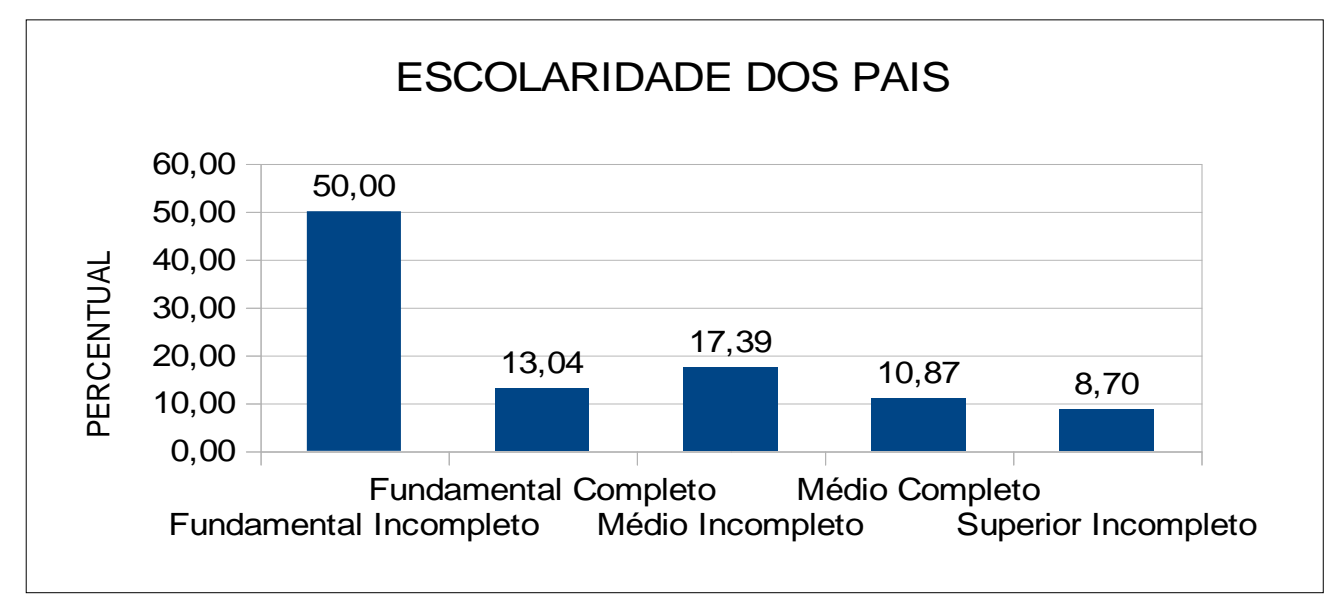

FONTE: Dados da pesquisa, 2015

Um aspecto observado que nos chama a atenção é que a grande maioria, 69,57\% pretende seguir nos estudos após o serviço militar, enquanto $30,43 \%$ não pretende mais estudar, o mesmo percentual dos que possuem o Ensino Fundamental Incompleto. 
GRÁFICO 7: Intenção de seguir os estudos

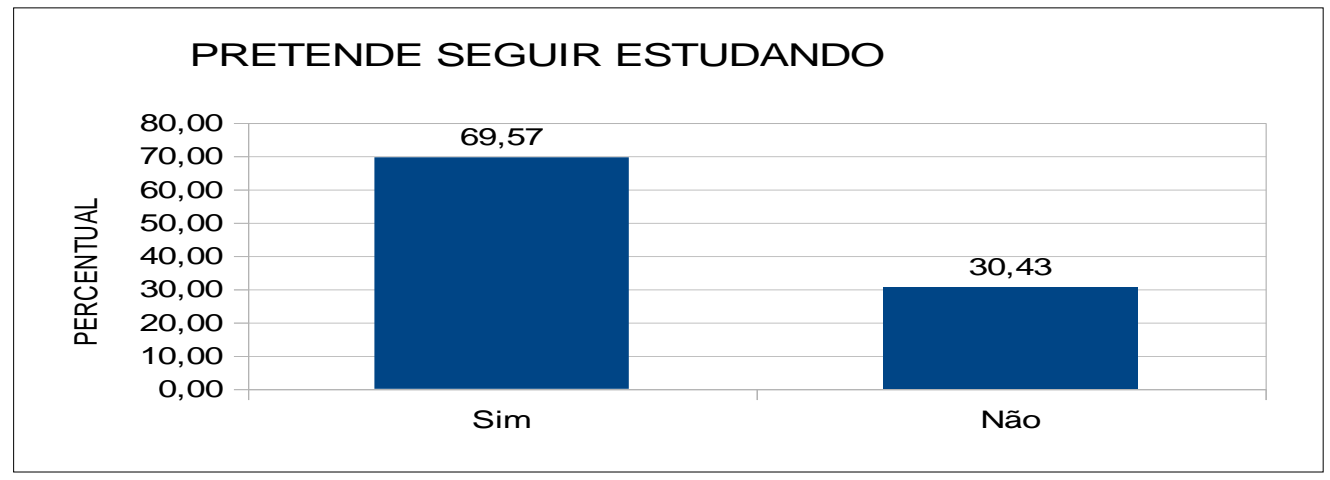

FONTE: Dados da pesquisa, 2015

O nível de conhecimento dos entrevistados sobre Meio Ambiente, demonstrou que os assuntos mais conhecidos são coleta seletiva de lixo e reciclagem, perfazendo um percentual de 30,95\%, seguido por reflorestamento, com 14,29\% e reaproveitamento de resíduos e preservação das águas com 11,9\%. (Gráfico 8)

GRÁFICO 8: Conhecimento sobre meio ambiente

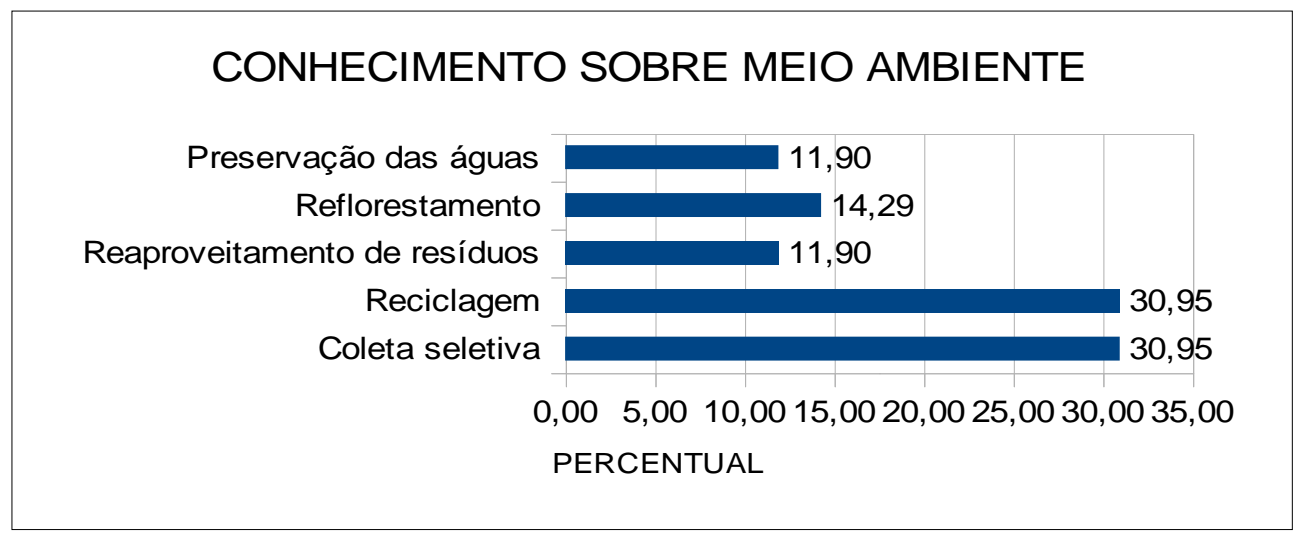

FONTE: Dados da pesquisa, 2015

Dando continuidade ao projeto, e dentro das atividades previstas na Instrução Individual Básica, foram intensificadas as instruções sobre Educação Ambiental, buscando despertar nestes jovens recrutas a importância do conhecimento sobre o assunto e a responsabilidade de cada um deles em difundir entre seus familiares e amigos a necessidade de se preservar e cuidar do local onde vivem.

A maioria dos jovens analisados apenas trabalhava, contribuindo para o sustento de suas famílias, enquanto a minoria trabalhava e estudava. A consequência desta opção, é que também a maioria dos analisados interrompeu os estudos, sem concluir o Ensino Fundamental (30,43\%) ou sem concluir o Ensino Médio (32,61\%). Esta é uma realidade preocupante, principalmente porque são jovens com 
idades entre 18 e 19 anos, que abandonam os estudos para ingressarem no mercado de trabalho sem uma formação específica.

Os assuntos coleta seletiva e reciclagem foram os que despertaram maior interesse e também foram os primeiros a serem lembrados. Cabe destacar que, desde o ano de 2014, esta Unidade do Exército mantém convênio com a Associação de Catadores Sepé Tiaraju do município de São Gabriel, onde duas vezes por semana são recolhidos aproximadamente 200 quilogramas de material reciclável, atividade esta desenvolvida com ampla campanha de conscientização junto a todos os integrantes da Organização Militar.

Este fato nos faz observar que muito mais que campanhas de conscientização em determinados períodos, a prática diária e efetiva no trato responsável com o assunto meio ambiente pode trazer resultados significativos. O reflexo das campanhas realizadas dentro do quartel e das instruções ministradas sobre este assunto mostram que estamos no caminho certo.

Durante a intervenção realizada, ao ministrar instruções sobre Educação Ambiental, os soldados nos revelaram que muitas vezes contribuíram para poluir o meio ambiente sem perceber, levados por hábitos julgados por eles como normais, por exemplo, jogando lixo na rua, nas valetas onde correm o esgoto a céu aberto na periferia da cidade, etc. e agiam assim de forma natural, sem avaliar o mal que estavam fazendo.

Nestes diálogos, comentamos também sobre o que aprenderam na escola a respeito do tema Educação Ambiental e muitos deles nos contaram que, em algumas escolas, eram realizadas atividades como produção de húmus, composteiras, confecção de brinquedos utilizando garrafas pet, dentre outras atividades .

Ao serem questionados se gostariam de participar de oficinas de construção de brinquedos com descartáveis, trazendo o conhecimento adquirido por eles lá na escola para difundir aos demais colegas, houve grande adesão e vontade de participar, comprovando assim, que as escolas cumprem o seu papel, mesmo com as dificuldades do dia a dia. Por incompatibilidade de tempo, não realizamos esta atividade, mas este estudo comprova que existe sim a possibilidade de tratar estes assuntos no âmbito das Forças Armadas, bem como dar maior espaço e visibilidade a outros temas tão importantes para a vida e para o futuro profissional destes cidadãos.

\section{CONSIDERAÇÕES FINAIS}

Os resultados do presente estudo comprovam que atitudes efetivas colocadas em prática nas atividades rotineiras, como ocorre na 13ª Companhia de Comunicações Mecanizada, apresentam resultados significativos.

Assim, verificamos que quando há uma participação realmente voltada para a prática e conscientização, tanto nas escolas de formação, quanto nas unidades de tropa, estas atitudes simples podem refletir no futuro desses cidadãos que hoje prestam o serviço militar inicial, mas que amanhã serão os responsáveis por difundir esta mentalidade de preservação ambiental.

Finalizando, observamos que esta mudança interior é um processo que se inicia desde a infância e que influencia a sociedade como um todo. Nada de novo, apenas o relembrar do significado de cidadania, de responsabilidade social, de viver em coletividade buscando o progresso da civilização enquanto "humanos". 
Com base nessas observações, podemos afirmar que muito ainda precisa ser feito. Os países ricos ditam as regras, definem metas de preservação ambiental, mas se recusam a rever suas formas de agir. Mesmo já tendo destruído a maioria de suas reservas florestais e poluído rios e oceanos, continuam a emitir poluentes, a diminuir a camada e ozônio, a contribuir para o aquecimento global e para o fim da humanidade.

Porém, enquanto cidadãos precisamos fazer a nossa parte, rever conceitos e dar sentindo à vida. Não somos "donos" do planeta, estamos aqui de passagem e outros virão. Que planeta eu quero deixar para meus filhos? Esta é a indagação que todas as pessoas conscientes deveriam fazer. Neste sentido o papel do Exército Brasileiro poderá ser importantíssimo para uma mudança de postura entre os jovens do país.

\section{REFERÊNCIAS}

ALENCASTRO, Mário Sérgio. Hans Jonas e a proposta de uma ética para a civilização tecnológica. Desenvolvimento e Meio Ambiente, n. 19, p. 13-27, jan./jun. 2009. Editora UFPR.

BECK, Ulrich. Risk society. London: Sage Publications, 1992.

BOFF, Leonardo. Sustentabilidade: O que é - O que não é. Petrópolis-RJ: Editora Vozes, 2012.

BRASIL. Exército. Portaria no 1138, de 22 Nov. 10. Aprova a Política de Gestão Ambiental do Exército Brasileiro, Brasília, 2010.

BRASIL. Exército. Regulamento Interno e dos Serviços Gerais (RISG). Brasília, 2003.

BRASIL. Lei 6.938/81. Política Nacional de Meio Ambiente.

BRASIL. Constituição (1824). Constituição do Império do Brasil: promulgada em março de 1824.

COSTA. Ronaldo Gonçalves de Andrade. Educação Ambiental Institucionalizada no Exército Brasileiro: (de) Limitações Epistemológicas das Práticas em Curso. Revista Eletrônica Mestrado em Educação Ambiental/FURG. Rio Grande, v. 20, p. 171$179,2008$.

CHAUÍ, Marilena. Convite à Filosofia. São Paulo - SP: Editora Ática, 2000.

ENCARNAÇÃO FILHO, Orlando Pessanha da. Processo de Recrutamento para o Serviço Militar: Uma Abordagem Sistêmica para a Excelência no Sistema De Gestão. Dissertação (Mestrado em Sistemas de Gestão)- Universidade Federal Fluminense, Niterói-RJ, 2003.

FRANCISCO, Papa. Encíclica Laudato Si. Disponível em:

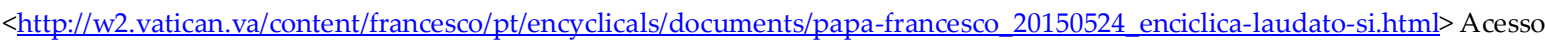
em: 17 ago. 2015.

JACOBI, Pedro. Educação ambiental, Cidadania e Sustentabilidade. Cadernos de Pesquisa, n. 118, p. 189-205, mar. 2003.

ANDRADE JÚNIOR, Hermes de. Limites e desafios aos militares brasileiros em relação à questão ambiental. Tese

(Doutorado)-Fundação Oswaldo Cruz.

REVISTA VEJA ON LINE. Serviço Militar Obrigatório. Disponível em:

$<\underline{\text { http://veja.abril.com.br/idade/exclusivo/perguntas respostas/servico-militar/servico-militar-obrigatorio-alistamento-exercito- }}$ dispensa.shtml> Acesso em: 12 abr. 2015.

ROCHA, Jefferson Marçal. Sustentabilidade em questão: Economia, sociedade e meio ambiente. Jundiaí-SP: Paco editorial, 2011.

FOLHA MILITAR. Alistamento Militar já está com prazo aberto. Disponível em: $<$ http://folhamilitar.com.br/2015/03/alistamentomilitar-ja-esta-com-o-prazo-aberto> Acesso em 04 abr. 2015.

VIEIRA, Licielo Romero. Eficiência Ambiental e Melhoria Econômica a partir da Gestão Ambiental em Órgãos Públicos: O caso da 13ํㅡㄹ Companhia De Comunicações Mecanizada em São Gabriel-RS. 2014. Monografia (Graduação em Gestão Ambiental)Universidade Federal do Pampa, São Gabriel, 2014. 